\title{
The Frequency of Cardiac Arrhythmias in Children with Congenital Heart Disease during Angiography
}

\author{
*Shoja Mohammad ${ }^{1}$, GhaderianMehdi ${ }^{2}$ and Shoja Mohsen ${ }^{3}$ \\ ${ }^{1}$ Department of Pediatric Cardiology, Isfahan University of Medical Sciences, Iran \\ ${ }^{2}$ Department of Pediatric Cardiology, Isfahan University of Medical Sciences, Iran \\ ${ }^{3}$ Epidemiologist in Bojnord University of medical science, Iran
}

Submission: January 22, 2017; Published: February 06, 2017

*Corresponding author: Shoja Mohammad, pediatric cardiologist fellow, Department of Pediatric Cardiology, Child Growth and Development Research Center, Isfahan University of Medical Sciences, Isfahan, Iran, email: Mshoja84@yahoo.com

\section{Abstract}

Background: Although non-invasive methods in the diagnosis of congenital heart disease have a special and wide place but as a practical method, angiography used widely for diagnosis and therapeutic intervention in children. Because importance of arrhythmias and their risks during angiography, we decided to determine the prevalence and types of arrhythmias occurred during cardiac catheterization.

Method: This cross-sectional study was performed in patients undergoing cardiac catheterization in Isfahan University of Medical Sciences during one year at pediatric ward of Chamran research and medical heart center.

Results: From 372 patients (185 males and 187 females) who underwent angiography, 172 patients had diagnostic and 200had interventional catheterization of the patients, 160 (43\%) had transient arrhythmias were less important during angiography and 15 (4.5\%) were experiencing sustain and important arrhythmias that need drug or electroshock to terminate or lead to complications and death in patient.

Conclusion: Arrhythmia in age groups under 15 year, low weight and interventional angiography was more happened but no significant relationship was found between arrhythmia and patient sex, type of disease (cyanotic or non-cyanotic), duration of angiography and history of cardiac surgery.

Keywords: Cardiac arrhythmia; congenital heart disease; cardiac catheterization

\section{Introduction}

Although new various non-invasive procedures such as echocardiography and imaging, in congenital heart disease diagnosis have a special place, but as a practical method at inefficiency of these modalities, cardiac angiography said to us the hidden aspects of the cardiac diseases.The field of cardiac catheterization has evolved, performing more interventional compared with diagnostic cases. In the meantime, the nature of interventional cardiology has changed, with a greater percentage of patients undergoing catheter-based intervention [1].

In recent years trend to perform some interventional angiography for cardiac lesions, naturally various side effects, including arrhythmias during the procedure more has happened $[2,3]$. With the development using of occlude in ASD and VSD closure and improvement of procedure techniques, especially the clinical application of Amplatzer in ASD and VSD occlusion, closure procedures of inter atrial and ventricular septal defects has been widely applied in clinical practice, featured with advantages of satisfying efficacy, little trauma, quick recovery after surgery, as well as few complications. However, there have been occasional reports of procedure complications due to inappropriate inclusion of cases, unqualified techniques of operators or lack of experience [4].

Arrhythmia is one the most common complications after surgery, which could severely affect the prognosis of children. In spite of advances in many noninvasive methods for studying cardiac lesions in children, angiography is still an essential method for the calculation of cardiovascular hemodynamic status. Accordingly, all adverse events related to cardiac catheterization are a major concern to pediatric cardiologists $[5,6]$. Given the importance of arrhythmias and dangers that 
can be happened during angiography, this article studied the prevalence and detection of arrhythmias type occurred during angiography while generating greater awareness and preparation of the medical team, equipment and medications, to provide timely treatment for patient [7-9].

\section{Methods}

In this cross-sectional study that was conducted, all patients between June 2014 and June 2015 in Isfahan Chamran research and medical heart center that had undergone angiography by pediatric cardiologists were studied. Inclusion criteria included patients undergoing angiography by pediatric service in this hospital. Exclusion criteria included patients undergoing angiography in this service that their files were incomplete. The patients were admitted to the hospital at the day before angiography. ECG of patients was taken during routine study. Before angiography, echocardiography was performed. All other documents of patients were assessed. Routine tests include: (CBC, ESR, CRP, BUN, Cr, Na, K, BS, PT, PTT, INR, U/A) done for patients. At least six hours before angiography they were fasted. In the absence of significant infectious problems, high fever and with normal general conditions angiography were done. If there was no problem in breathing during angiography, an anesthesiologist did not intubate the patient, and with midazolam and ketamine, deep sedation was performed.

Oxygen and Capnography monitors were performed during the procedure, and cardiac monitoring was done. During angiography iso-osmolar contrast were used for imaging. After the angiography and sheet exit, patients were transferred to beds with cardiac monitoring and unstable patients are transferred to intensive care unit. The patient's with unconsciousness does not eat anything until complete consciousness and then feeding start. Patients that had simple diagnostic catheterization without complication and good general condition, discharged the same day and if the general condition is unfavorable or intervention is taken, usually discharged the next day.

Data obtained from patient file records by using a selfmade checklist. Information such as the type of angiography (a diagnostic or interventional), type and length of arrhythmia, the need for medication or electroshock to terminate the arrhythmia, the patient's age and other demographic information needed were extracted. Ethical considerations of confidentiality of information and need to disseminate the results of the study as a whole and not the individual, was considered. The data of this study by using descriptive statistics and independent t-test, chi-square and Fisher exact test were analyzed with statistical software SPSS18.

\section{Results}

Of the 372 patients in the study who had undergone angiography, 185 were men. 113 children were smaller than one year, 134 patients between one to six years and 125 above 6 years of age. 28 patients weight were below $5 \mathrm{~kg}, 124$ between $5 \mathrm{~kg}$ $-10 \mathrm{~kg}$, and 220 above $10 \mathrm{~kg}$. Angiography in 172 cases (46\%) of patients in the study had been done for diagnostic reasons, and in 200 cases was interventional. In 352 cases (95\%) the duration of angiography was 30 to 60 minutes, in 9 under half an hour and in 11 took more than one hour. 105 patients (28 percent) had cyanotic heart disease and 267 patients (72\%) had no cyanosis.

Of 372 patients in this study, 175 patients (47\%) were experiencing arrhythmia. 137 cases had transient PVC, 30 cases had transient bradycardia, 6 cases had transient PSVT, 1 case transient PAC, and 1 case cardiac arrest. From total 175 cases of arrhythmia, in 160 cases arrhythmia were cut without medication, in 14 cases arrhythmia terminate with medication (a PVC that needs to be injected lidocaine, 12 cases of bradycardia with atropine returned, and one of PSVT who replied to the adenosine) and one needed ECT (unfortunately she was a 8 months old that has dilated cardiomyopathy due to ALCAPA, her LVEF was very low and didn't response to medication, ECT and resuscitation).

The incidence of arrhythmia during angiography is most in age group under 15 years but in group older than 15 years, greatly reduced $(\mathrm{p}=0.007)$. There was a significant relationship between the weight and the occurrence of arrhythmia and so in the weight of upper than $10 \mathrm{~kg}$, reduced the incidence of arrhythmias during angiography ( $p=0.05)$. There was significant relationship between the reason of angiography (diagnostic, interventional) and arrhythmia so that arrhythmia in interventional angiography was most viewed $(p=0.01)$.

No significant relationship between sex and cardiac arrhythmia during angiography was found ( $p=0.23$ ). Between cyanotic and non-cyanotic cardiac disease and arrhythmia was no significant relationship ( $\mathrm{p}=0.31$ ). Between the duration of angiography and cardiac arrhythmia no relationship was observed $(p=0.19)$. The incidence of arrhythmias in children who have had history of cardiac surgery and children who had no cardiac surgery were no significant difference seen $(p=0.49$ ). No significant relationship between type of arrhythmia during angiography and sex, weight, age, reason of angiography(diagnostic, interventional), cyanotic and noncyanotic cardiac disease, duration of angiography and history of cardiac surgerywas found ( $\mathrm{p}=0.35$ ).

\section{Discussion}

Mah DY et al. $[10,11]$ in a study of 6183 patients who had undergone angiography during six years, studied the incidence of heart block $[10,11]$. Among these patients, 135 cases had heart block. The patients' average weight was $15 \mathrm{~kg}$, $29 \%$ of them were under one year. Among the patients $72 \%$ had complex heart disease. Angiography time of over than two hours was identified as one of the risk factors for heart block. $97 \%$ of these patients (135 cases that had complete heart block) recovered within a 
week, but others require pacemaker for treatment of heart block. In our study and this article, incidence of arrhythmias that didn't required medication for termination are similar together and the prevalence of serious arrhythmias that requiring pharmacological or intervention is greater in our study. Because in our study type of arrhythmias differed and these arrhythmias required medication, no pacemaker. Greater incidence in the down age and weight was similar to this study.

Yilmazer MM et al. [12] analyzed 519 catheterization procedures performed over a period of two years retrospectively [12]. Several risk factors related to the patient or catheterization was analyzed. The incidence of complications was $6.2 \%$. The most common major and minor complications were arterial thrombosis that required intervention and transient arrhythmias, respectively. The independent risk of any complication was greatest up to 1 year of age $(p=0.02)$. The risks of a major complication $(p=0.003)$ and development of arterial thrombosis $(p=0.02)$ were significantly greater in patients $<1$ year of age by univariate analysis. Younger age, particularly $<1$ year of age, is the strongest predictor of development of any complication. In our study, the prevalence of transient arrhythmias is high and in this article is similar to our study and was be the second complication in their patients. Greater incidence in the down age and weight was similar to our study.

Odegard KC et al. [2] in study of 7289 patients, who underwent angiography for 5 years between 2004 and 2009, examined the incidence of cardiac arrest [2]. And their definition was included cases of cardiac arrest that leads to cardiac massage to resuscitate the patient. Among these patients 70 cases had cardiac arrest, of which 69\% were successful resuscitation with massage. And $26 \%$ were in need of ECMO machine and 4 patients were not restored. Sudden cardiac arrhythmia was the causes of cardiac arrest in 54\% of cases. $71 \%$ took less than 11 minutes recovery time [13-17]. The difference between our study and this article is that incidence of cardiac arrest in our study was one patient between 372 cases (lower than this article) but reason of this difference probably is population number in this article that is greater than our patients.

Overall the difference between our study and previous studies was that all types of arrhythmias occurred during angiography, were examined in our study. That because of arrhythmia compared to previous studies, is seems greater in incidence [3]. But not transient arrhythmias that were controlled with medication or lead to complications or dying patients are approximately in the range of previous studies.

\section{Limitations of the Study}

The study population because of the incompleteness of patient records is lower than other studies and overall the case population is lower than other centers, so we suggest the wide study in this topic with wide range of time and population.

\section{Conclusion}

Considering the importance and prevalence of arrhythmias and their variants during angiography and the risks that can be diagnosed, can say in patients with complex cardiac disease with low age and weight which the interventional angiography takes place , medical teams also should be aware of and prepare the equipment and provide medications, for timely treatment underlying problem in these patients.

\section{References}

1. Mah DY, Porras D, Bergersen L, Marshall AC, Walsh EP, et al. (2014) Incidence of and risk factors for catheterization-induced complete heart block in the pediatric cardiac catheterization laboratory. Circ Arrhythm Electrophysiol 7(1): 127-133.

2. Odegard KC, Bergersen L, Thiagarajan R, Clark L, Shukla A, et al. (2014) The frequency of cardiac arrests in patients with congenital heart disease undergoing cardiac catheterization. Anesth Analg 118(1): 175-182.

3. Phillips BL, Cabalka AK, Hagler DJ, Bailey KR, Cetta F (2010) Procedural complications during congenital cardiac catheterization. Congenit Heart Dis 5(2): 118-123

4. Jin M, Ding WH, Wang XF, Guo BJ, Liang YM, et al. (2015) Value of the Ratio of Occluder Versus Atrial Septal Length for Predicting Arrhythmia Occurrence after Transcatheter Closure in Children with OstiumSecundum Atrial Septal Defect, Chin Med J (Engl) 128(12): 1574-1578.

5. Johnson JN, Marquardt ML, Ackerman MJ, Asirvatham SJ, Reeder GS, et al. (2011) Electrocardiographic changes and arrhythmias following percutaneousatrial septal defect and patent foramen ovale device closure. Catheter Cardiovasc Interv 78(2): 254-261.

6. Al-Anani SJ, Weber H, Hijazi ZM (2010) Atrioventricular block after transcatheter ASD closure using the Amplatzer septal occluder: risk factors and recommendations. Catheter Cardiovasc Interv 75(5): 767772.

7. Verheij G, Smits Wintjens V, Rozendaal L, Blom N, Walther F, Lopriore E (2009) Cardiac arrhythmias associated with umbilical venous catheterisation in neonates. BMJ Case Rep pii: bcr04.2009.1778.

8. Szkutnik M, Lenarczyk A, Kusa J, Białkowski J (2008) Symptomatic tachy- and bradyarrhythmias after transcatheter closure of interatrial communications with Amplatzer devices. Cardiol J 15(6): 510-516.

9. Xie YM, Zhang ZW, Li YF, Qian MY, Wang HS (2005) Management of the arrhythmia around the procedure of transcatheter closure of ventricular septal defects in pediatric patients. Zhonghua Xin Xue Guan Bing Za Zhi 33(12): 1092-1094.

10. Ko Eun Lee, Yeon Jeong Seo, Gi Beom Kim, Hyo Soon An, Young Hwan Song, et al. (2016) Complications of Cardiac Catheterization in Structural Heart Disease. Korean Circ J 46(2): 246-255.

11. Rohit MK, Puri K, Vadivelu R (2014 ) Reversible complete atrioventricular block after percutaneous ASD device closure in a child $<15$ kg. Indian Heart J 66(3): 366-369.

12. Yilmazer MM, Ustyol A, Güven B, Oner T, Demirpençe S, et al. (2012) Complications of cardiac catheterization in pediatric patients: a single center experience. Turk J Pediatr 54(5): 478-485.

13. Mori Y, Takahashi K, Nakanishi T (2013) Complications of cardiac catheterization in adults and children with congenital heart disease in the current era. Heart Vessels 28(3): 352-359. 
14. da Silva PS, Waisberg J (2010) Induction of life-threatening supraventricular tachycardia during central venous catheter placement: an unusual complication J Pediatr Surg 45(8): E13-16.

15. Huang YC, Chang JS, Lai YC, Li PC (2009) Importance of prevention and early intervention of adverse events in pediatric cardiac catheterization: a review of three years of experience Pediatr Neonatol 50(6): 280-286
16. Al-Anani SJ, Weber H, Hijazi ZM (2010) Atrioventricular block after transcatheter ASD closure using the Amplatzer septal occluder: risk factors and recommendations Catheter Cardiovasc Interv 75(5): 767772 .

17. King MA, Garrison MM, Vavilala MS, Zimmerman JJ, Rivara FP (2008) Complications associated with arterial catheterization in children. Pediatr Crit Care Med 9(4): 367-371.

\section{Your next submission with Juniper Publishers} will reach you the below assets

- Quality Editorial service

- Swift Peer Review

- Reprints availability

- E-prints Service

- Manuscript Podcast for convenient understanding

- Global attainment for your research

- Manuscript accessibility in different formats (Pdf, E-pub, Full Text, Audio)

- Unceasing customer service

Track the below URL for one-step submission https://juniperpublishers.com/online-submission.php 